\title{
Assessment of Spatial Models using Ground Point Data: Soil Matrix and Radiometric Approach
}

\author{
S.J. Hill ${ }^{\mathrm{a}}$, G.R. Hancock ${ }^{\mathrm{a}}$ and G.R Willgoose ${ }^{\mathrm{b}}$
}

${ }^{a}$ School of Environmental and Life Science, University of Newcastle, Callaghan, New South Wales, Australia ${ }^{b}$ School of Engineering, University of Newcastle, Callaghan, New South Wales, Australia Email:s.j.hill@uon.edu.au

\begin{abstract}
In this paper we present an assessment of the national airborne radiometrics model (NARM) using point based field data (soil samples) using landscape properties of topography, soils and geology. The Krui catchment, in north-west of the Hunter Valley NSW, Australia was used as the study site. Soils were sampled across two scales, and ${ }^{40} \mathrm{~K}$ concentration of the soil samples determined. Relationships between the field ${ }^{40} \mathrm{~K}$ and NARM ${ }^{40} \mathrm{~K}$ were investigated using a digital elevation model, the national soil atlas model and the national geology model.

Our results showed that the NARM and field data are correlated and that this correlation extends across changing soil types and geology. A complex relationship with topographical features was also determined which needs further investigation.
\end{abstract}

Keywords: $\quad$ Radiometric model, field testing, model assessment, potassium, soils 


\section{INTRODUCTION}

Advances in data collection and computer processing power have led to the development of complex temporal and spatial models in recent years. In order to answer complex questions in environmental science adoption of spatial models has occurred (Finke 2012) enabling quantitative studies into the complex system of landscapes which previously was only possible qualitatively. This adaptation of modeling has particularly been prevalent in soil science (Minasny et al. 2008) with landscape evolution spatial models and pedogenesis modeling (Willgoose et al. 2012) being developed and modeling becoming a topic of interesting in multidisciplinary studies.

Digital soil mapping (DSM) is the primary form of spatially available information on soils. Soil mapping has been a central part of soil science for nearly a century (Hudson 1992), with pseudo-quantitative classification of soils under strict frameworks (Northcote 1971) utilized to depict boundaries of soil type across landscapes. DSM originated as digital formats from previous cartographical information. Understanding of soil formation, properties and evolution has become imperative in understanding global ecosystem (Bouma 2009; Grunwald et al. 2011; Hartemink et al. 2008), with soils playing a pivotal role in global climate mitigation reserach. The world soil map project was created to bridge these issues with international collaboration to collect and maintain stores of soil legacy data and DSM (Carré et al. 2009). Australia has made considerable contributions to the international community with the creation and continued development of the Australian soil atlas (CSIRO 1991). Spatial models on a national scale in Australia are continuously being developed.

The national airborne radiometrics model (NARM) is a spatial radiometric element dataset produced for Australia (Geoscience Australia 2010). Radiometric element data has been proposed as an independent means of earth surface analysis previously only achieved through physical analysis. NARM has been used to create a national weathering index model (Wilford 2012). Complex environmental spatial models are developed with physical calibrations (Cohen et al. 2009) however there is limited published assessment of spatial models with independent sets of physical sites.

Quantitative models are created through logical mathematical relationships. Spatial models need to be assessed using observable field parameters, in conjunction with the landscape properties of the field location. This research represents a preliminary investigation of the relationships between the NARM and field sample data for ${ }^{40} \mathrm{~K}$ across a landscape with changing geology, topography and soils.

\section{SITE DESCRIPTION}

The study site used in this research is the Krui River catchment and one of its sub-catchments (the Stanley River). The Krui catchment is located in the north-west of the Hunter region of New South Wales, Australia (Figure 1). The geology is primary basaltic (map unit Czwl) with sedimentary deposits along the river channel (map units Jisp and Qa) (Offenberg 1971; Rasmus et al. 1969). The catchment has seven soil types, with cracking clays being the dominant type (CSIRO 1991). Five of the soil types are sampled in this study, basaltic soils (soil atlas classes Kb2 and Ke11), cracking clays (atlas class Kd3), red earths (atlas class Mo1) and yellow earths (atlas class Ms1). The elevation range across the Krui catchment is $100 \mathrm{~m}$ to $1200 \mathrm{~m}$. Some moderate climate variability is noted across the catchment with increased elevation. 

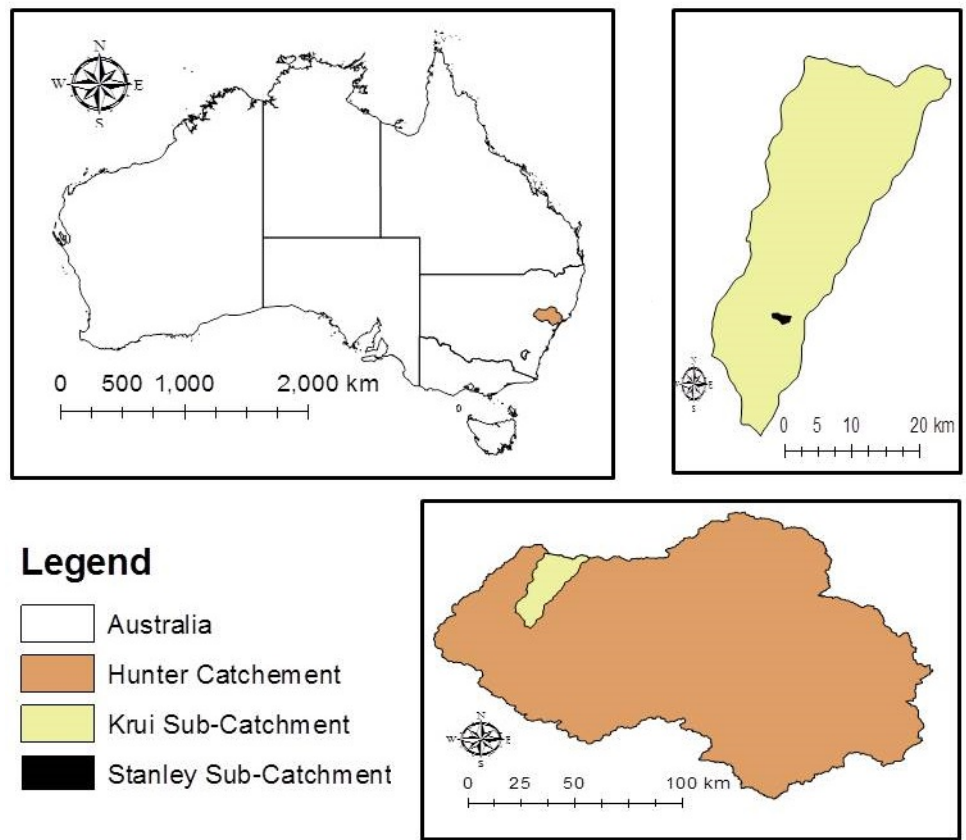

Figure 1: The Krui River catchment (upper right panel) is a sub-catchment of the Hunter River (lower right panel) in NSW, Australia. Data derived from national catchment boundaries (Geoscience Australia 2011b).

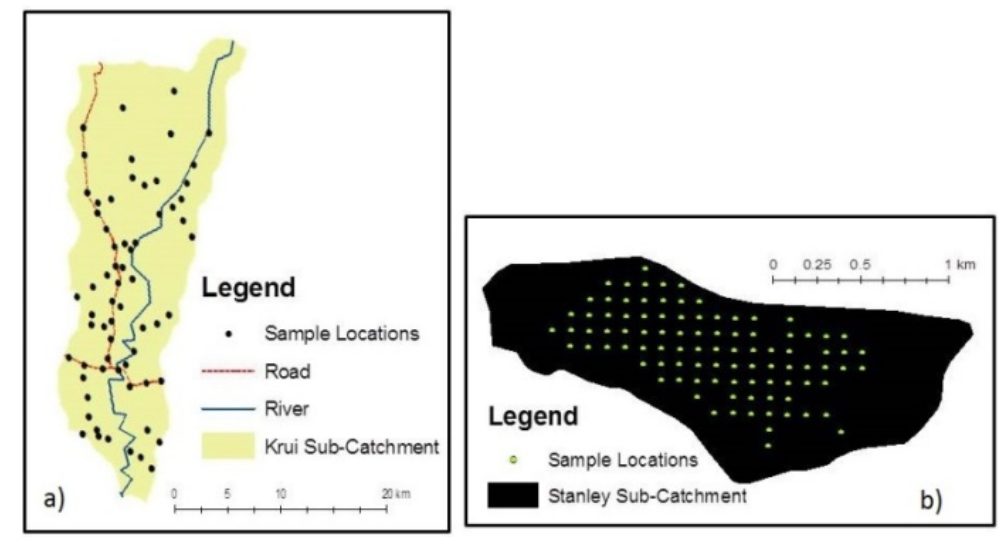

Figure 2: Sample Locations within Study Sub-Catchments. Krui sub-catchment sample locations, b) Stanley sub-catchment sample locations

\section{METHODS}

\subsection{Field Data}

Field soil samples were collected across two scales; across the Krui catchment (Figure 2a) and on a $100 \mathrm{~m}$ grid pattern in the Stanley sub-catchment (Figure $2 \mathrm{~b}$ ). Sample location was noted using Universal Transverse Mercator (UTM) coordinates, for which corresponding attributes of elevation, slope, soil type and geology were obtained. Samples were taken by penetration of $94 \mathrm{~mm}$ by $200 \mathrm{~mm}$ circular cores into the land surface until flush with soil surface and removed through excavation of the surrounding soil. Sample analysis was undertaken with the use of agronomic methods. Samples were dried in a laboratory at $\sim 40^{\circ} \mathrm{C}$ in an oven for up to 7 days until all moisture in the sample was removed and then sieved at $2 \mathrm{~mm}$. Samples with a mass between 300 grams and 1000 grams of the sieved soils were placed in a Marinelli beaker on a hyperpure germanium detector to detect potassium $40\left({ }^{40} \mathrm{~K}\right)$ and samples were counted for a minimum of 8 hours (i.e. 28800 counts) and a maximum of 24 hours (i.e. 86400 counts). Results were converted to counts per minute per kilogram $(\mathrm{cpm} / \mathrm{kg})$ of ${ }^{40} \mathrm{~K}$ and used to test the NARM. 


\subsection{Digital Spatial Data}

This research used four digital data sets, the NARM (Geoscience Australia 2010), 9 arc-second digital elevation model (DEM) (Geoscience Australia 2011a), national geology model (Geoscience Australia 2009) and national soil atlas (CSIRO 1991). The NARM and DEM data sets were at $250 \mathrm{~m}$ resolution. The national geology model is at 1:1,000,000 scale and the national soil atlas in on the 1:2,000,000 scale. Topographic slope was derived from the DEM.

NARM has several layers. Some of the NARM layers are weighted combinations of all three parameters (thorium, uranium and potassium). The layer selected for this study was the non-filtered ${ }^{40} \mathrm{~K}$ layer derived in 2010. There is no conclusive information on the most suitable spatial layer for physical assessment.

Therefore the non-filtered spatial layer was chosen. Investigation into other spatial layers of NARM may produce alternate findings.

\section{RESULTS}

\subsection{Ground Validation}

The NARM and field samples have a weak but statistically significant relationship across the Stanley (pvalue $0.003, \mathrm{r}^{2} 0.15, \mathrm{n} 92$ ) and Krui (p-value $\left.<0.001, \mathrm{r}^{2} 0.09, \mathrm{n} 101\right)$ catchments (Figure 3 ). The NARM and field data ${ }^{40} \mathrm{~K}$ distributions are not statistically different between the two study catchments (Figure 4 and Table 1).
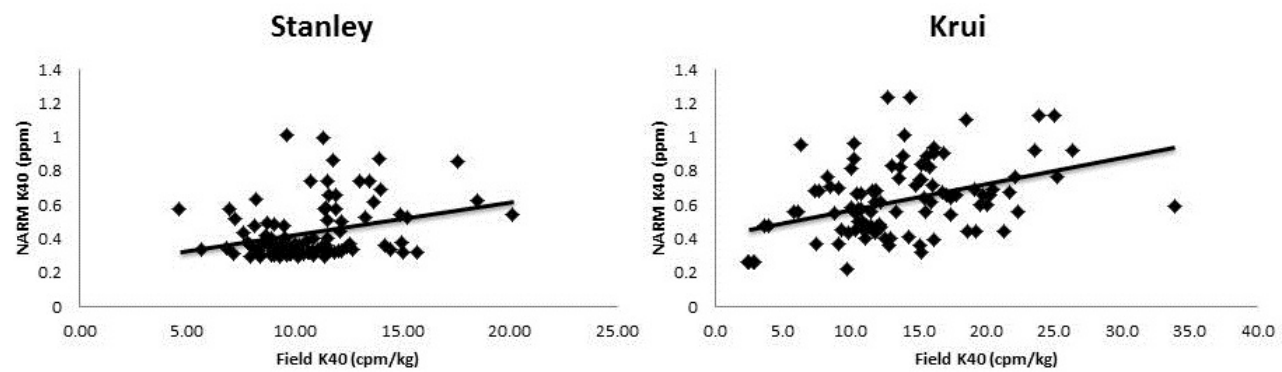

Figure 3. NARM and Field ${ }^{40} \mathrm{~K}$ Correlation for Stanley and Krui Catchments.
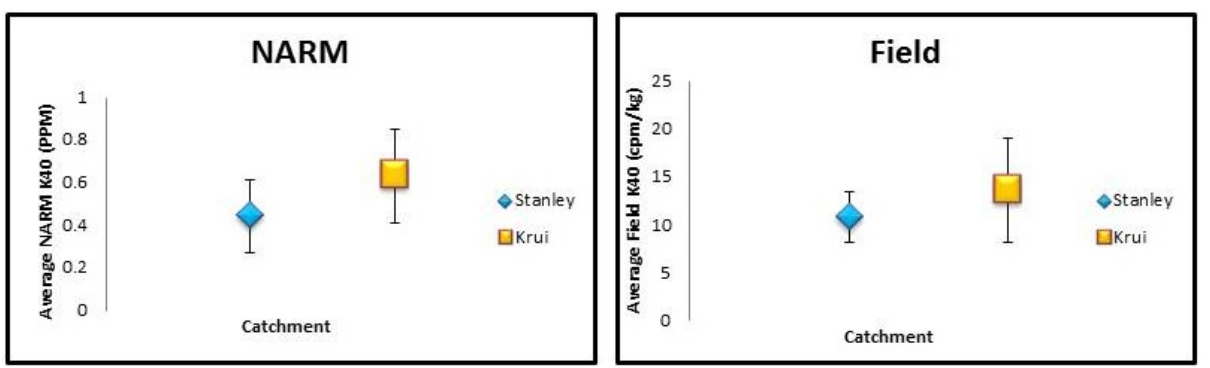

Figure 4. ${ }^{40} \mathrm{~K}$ of Stanley and Krui catchments for NARM and field samples.

\subsection{Stanley Catchment}

The field sample data at Stanley has no significant relationship with elevation or slope (p-value 0.19 and 0.86 respectively, $\mathrm{n}$ 92). The NARM data relates significantly to elevation and slope (p-value $<.0001$ respectively), and the NARM has a significant polylinear relationship (p-value $<0.001, \mathrm{r}^{2} 0.92$, n 92) with elevation (Figure 5). 
S.J Hill et al., Assessment of Spatial Models using Ground Point Data...

Table 1. Statistical information for Stanley and Krui catchment NARM and field 40K.

\begin{tabular}{|l|l|l|l|l|}
\hline \multirow{2}{*}{} & \multicolumn{2}{|c|}{ NARM } & \multicolumn{2}{c|}{ Field } \\
\cline { 2 - 5 } & Stanley & Krui & Stanley & Krui \\
\hline$\chi$ & 0.4 & 0.6 & 10.8 & 13.6 \\
\hline S.D. & 0.17 & 0.22 & 2.6 & 5.5 \\
\hline $\max$ & 1.01 & 1.2 & 20.2 & 33.9 \\
\hline $\min$ & 0.29 & 0.22 & 4.7 & 2.4 \\
\hline $\mathrm{n}$ & 92 & 101 & 92 & 101 \\
\hline
\end{tabular}

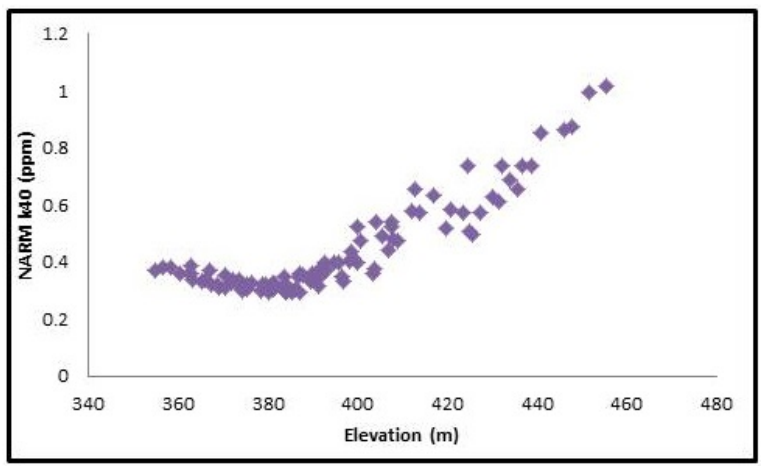

Figure 5. NARM ${ }^{40} \mathrm{~K}$ Relationship with elevation, Stanley catchment.

\subsection{Krui Catchment}

The NARM data has no significant relationship to elevation or slope (p-value 0.08 and 0.2 respectively, $n$ 101). The field sample data has no significant relationship to elevation ( $p$-value 0.76). However, the field samples have a significant (p-value 0.0001) inverse relationship $\left(\mathrm{r}^{2} 0.14\right)$ with slope. The relationship between NARM and field samples varies across soil type and geology (Table 2). However NARM and field samples have similar trends across soil types and geology (Figure 6). Further investigation into the slope and field samples relationship indicates that the slope and field data varies across soil type and geology with slope and field data observing similar trends across soil types, while the slope and field data have an inverse relationship across geological groups (Figure 7).

Table 2. Statistical factors of $\mathrm{R}^{2}$ and $\mathrm{P}$ for the NARM and field ${ }^{40} \mathrm{~K}$ relationship stratified by soil type and geology.

\begin{tabular}{|l|l|l|l|l|}
\hline Classification & Variable & $\mathrm{R}^{2}$ & $\mathrm{P}$ & $\mathrm{n}$ \\
\hline \multirow{4}{*}{ Soil Type } & $\mathrm{Kb} 2$ & 0.07 & 0.16 & 28 \\
\cline { 2 - 5 } & $\mathrm{Kd} 3$ & N/A & N/A & 2 \\
\cline { 2 - 5 } & $\mathrm{Ke} 11$ & 0.40 & $<.0001$ & 60 \\
\cline { 2 - 5 } & Mo1 & 0.02 & 0.03 & 5 \\
\cline { 2 - 5 } & Ms1 & 0.75 & 0.7 & 6 \\
\hline \multirow{3}{*}{ Geology } & Czwl & 0.07 & 0.03 & 83 \\
\cline { 2 - 5 } & Jsip & 0.34 & 0.03 & 8 \\
\cline { 2 - 5 } & Qa & 0.49 & 0.005 & 10 \\
\hline
\end{tabular}




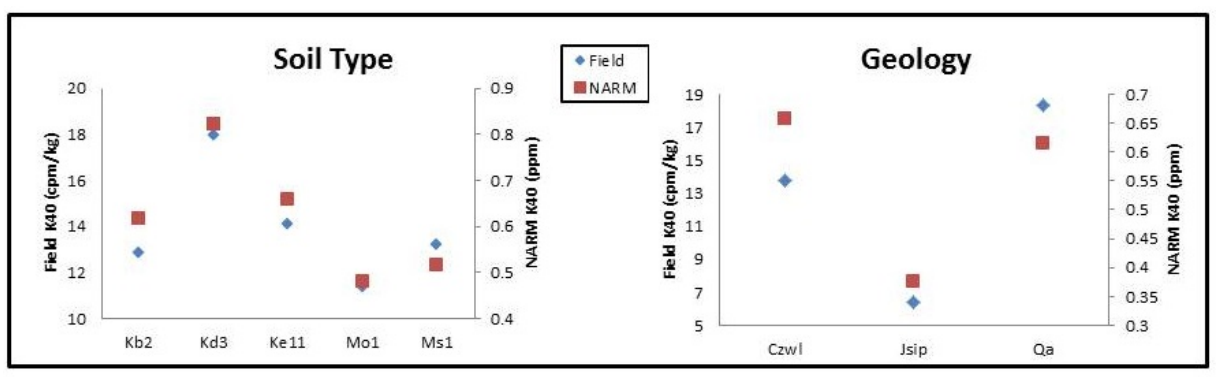

Figure 6. NARM and Field ${ }^{40} \mathrm{~K}$ relationship across soil type and geological classes.

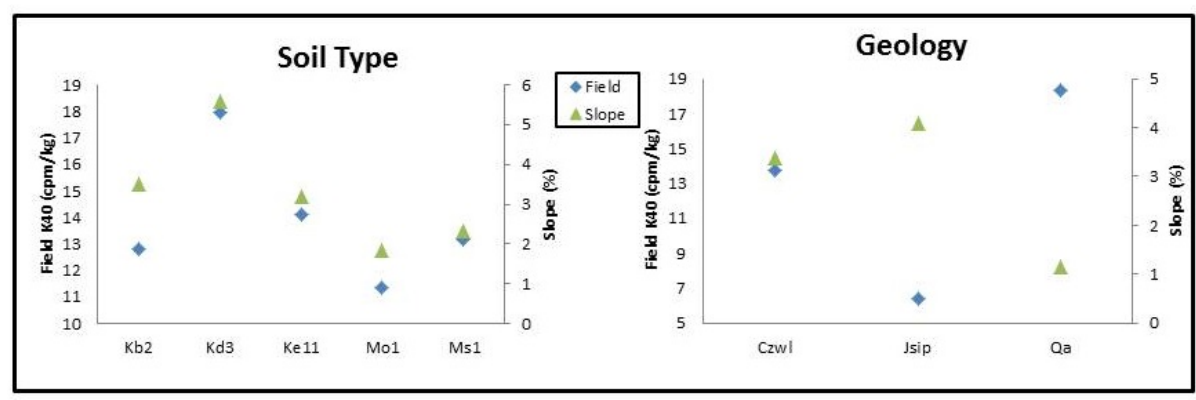

Figure 7. Relationship between field ${ }^{40} \mathrm{~K}$ and slope across soil type and geological classes.

\section{DISCUSSION}

The findings indicate that at this study site there is a significant relationship between elevation and slope gradient, but that this is not consistent across the spatial scales investigated. Further investigation into the topographical attributes and ${ }^{40} \mathrm{~K}$ of the NARM and field samples is needed, through further analysis of topographical bias of NARM and consistency of measured ${ }^{40} \mathrm{~K}$ in field samples.

The relationship between the NARM and field data indicate that soil type is a dominant factor in this relationship. Different soil types may have different processes for the movement of soluble potassium within the matrix, however little research has been undertaken to determine the relationship between soluble potassium and ${ }^{40} \mathrm{~K}$ which was measured in this research. The dominance of slope on this relationship maybe artificial as this study is limited in the degree of topographical investigation and may be caused by other topographical factors (e.g. aspect and up slope contributing area). Further investigation is needed to determine the relationships between topographical, geological, soil and other environmental factors affecting the measured ${ }^{40} \mathrm{~K}$ in the soil and NARM.

Assessment of NARM with the field samples was achieved, with NARM and field ${ }^{40} \mathrm{~K}$ being significantly correlated. This is despite the ${ }^{40} \mathrm{~K}$ of the field samples being measured using only the $2 \mathrm{~mm}$ fraction, and thus not the full source of the ${ }^{40} \mathrm{~K}$ "seen" by the sensor. Even with changing environmental factors of soil type and geology NARM and the field samples were correlated. The airborne potassium spectrometry is a reliable means of determining surface soil ${ }^{40} \mathrm{~K}$ spatial distributions at these study sites. Expansion of the study area is needed for further validation of the results.

The methodology presented in this research has allowed for the assessment of the NARM against field samples. This research is based within soil science; however this methodology can be taken and used for assessment of other environmental models. With further experimentation, application of this methodology can become a staple in spatial model acceptance in traditional environmental sciences. NARM has potential for expansion into predictive soil spatial modeling and is a useful and validated data set for soil spatial analysis.

\section{CONCLUSION}

This paper presents a methodology for the assessment of the national airborne radiometrics model with point based field data. The correlation between these two digital data sets was assessed along with the influences of topography, soils and geology on this relationship. This research found that the NARM and field ${ }^{40} \mathrm{~K}$ were correlated and that this correlation extends across changing soil types and geology. A complex relationship with topographical features was also determined that needs further investigation. 
The use of NARM and other spatially distributed datasets may produce more understanding of geological, geographical and pedogenesis drivers. This research validates the use of NARM to investigate these drivers and with further investigation has the potential to aid in environmental modeling. Further investigation into the other radioelements available in the NARM datasets of uranium and thorium may lead to greater understanding of physical systems. Further investigation is currently being undertaken into soil spatial distribution and depth analysis which may also lead to insights into ${ }^{40} \mathrm{~K}$ dynamics in the soil matrix. This research is the tip of the iceberg in understanding how airborne radiometrics can be used in understanding terrestrial environments.

\section{ACKNOWLEDGEMENTS}

This research could not be possible without the preliminary work of Cristina Martinez and Annelise Bissett in the collection of soil samples used in this research. This work was also completed with the technical assistance of Chris Dever.

\section{REFERENCES}

Bouma J. (2009) Soils are back on the global agenda: Now what? Geoderma 150(2), 224-225.

Carré F., Hartemink A.E., Hempel J., Huising J., Lagacherie P., Mcbratney A.B., Mckenzie N.J., De M., Mendonçasantos L., Minasny B., Montanarella L., Okoth P., Palm C.A., Sachs J.D., Shepherd K.D., Vågen T., Vanlauwe B., Walsh M.G., Winowiecki L.A., Zhang G. (2009) Digital Soil Map of the World. Science 325, 680-681.

Cohen S., Willgoose G.R., Hancock G.R. (2009) The mARM spatially distributed soil evolution model: A computationally efficient modeling framework and analysis of hillslope soil surface organization. Journal of Geophysical Research 114(F3), F03001.

CSIRO (1991) Digital Atlas of Australian Soils.

Finke P.A. (2012) On digital soil assessment with models and the Pedometrics agenda. Geoderma 171-172, 3-15.

Geoscience Australia (2009) National Geology Model.

http://www.ga.gov.au/products/servlet/controller?event=GEOCAT DETAILS\&catno=74619

Geoscience Australia (2010) Radiometric Map of Australia. http://www.ga.gov.au/minerals/disciplines/geophysics/radiometrics.html

Geoscience Australia (2011a) 9 Second DEM

http://www.ga.gov.au/topographic-mapping/digital-elevation-data.html

Geoscience Australia (2011b) National Catchment Boundaries Version 1.1.4 http://www.ga.gov.au/meta/ANZCW0703014235.html

Grunwald S., Thompson J.A., Boettinger J. (2011) Digital Soil Mapping and Modeling at Continental Scales: Finding Solutions for Global Issues. Soil Science Society of America Journal 75(4), 1201-1213.

Hartemink A.E., McBratney A. (2008) A soil science renaissance. Geoderma 148(2), 123-129.

Hudson B.D. (1992) The soil survey as paradigm-based science. Soil Science Society of America Journal 56(3), 836-841.

Minasny B., McBratney A.B., Salvador-Blanes S. (2008) Quantitative models for pedogenesis - A review. Geoderma 144(1-2), 140-157.

Northcote K.H. (1971) 'A Factual Key for the Recognition of Australian Soils.' 3rd edn. (Commerical Pritning House Pty Ltd: Adelaide)

Offenberg A.C. (1971) Tamworth. Sheet SH 56-13, 1:250,000 Geological Series.

Rasmus P.L., Rose D.M., Rose G. (1969) Singleton. Sheet S1 56-1, 1:250,000 Geological Series.

Wilford J. (2012) A weathering intensity index for the Australian continent using airborne gamma-ray spectrometry and digital terrain analysis. Geoderma 183-184, 124-142.

Willgoose G.R., Hancock G.R., Cohen S. (2012) The potential role of pedogenesis modelling in digital soil mapping. In 'Digital Soil Assessment and Beyound.' (Eds B Minasny and AB Mcbratney) pp. 129-134. (Taylor \& Francis Group: London) 